\title{
Stage and tissue-specific prognostic impact of miR-182 in NSCLC
}

Helge Stenvold ${ }^{1,2^{*}}$, Tom Donnem ${ }^{1,2}$, Sigve Andersen ${ }^{1,2}$, Samer Al-Saad ${ }^{3,4}$, Lill-Tove Busund ${ }^{3,4}$ and Roy M Bremnes S $^{1,2}$

\begin{abstract}
Background: MicroRNA (miR)-182 is frequently upregulated in cancers, has generally been viewed as an oncogene and is possibly connected to angiogenesis. We aimed to explore what impact miR-182 has in non-small cell lung cancer (NSCLC), and more explicitly its correlation with angiogenic markers.

Methods: From 335 unselected stage I to IIIA NSCLC carcinomas, duplicate tumor and tumor-associated stromal cores were collected in tissue microarray blocks (TMAs). In situ hybridization (ISH) was used to detect the expression of miR-182 in tumor cells, and immunohistochemistry (IHC) was used to detect the expression of angiogenesis related protein markers.

Results: In univariate analyses, high tumor cell expression of miR-182 was a positive prognostic factor for patients with squamous cell carcinoma ( $S C C, P=0.042)$ and stage II patients $(P=0.003)$. Also in the multivariate analysis, high tumor cell miR-182 expression was associated with a good prognosis in the same groups (SCC: HR 0.57, Cl 95\% 0.33-0.99, $\mathrm{P}=0.048$; stage II: HR 0.50, Cl 95\% 0.28-0.90, P=0.020). We found significant correlations between miR-182 and the angiogenesis related markers FGF2, HIF2 $a$ and MMP-7.
\end{abstract}

Conclusion: In patients with SCC and in stage II patients, high tumor cell miR-182 expression is an independent positive prognostic factor.

Keywords: NSCLC, Stage I-IIIA, Survival, Prognostic impact, miR-182, miRNA

\section{Background}

Lung cancer is, despite a small decline in mortality recent years, still the number one killer among cancers [1]. Non-small cell lung cancer (NSCLC) accounts for 80$85 \%$ of all lung cancers. Optimization of treatment with better surgery, cytotoxic agents and radiation therapy has not altered the prognosis much. We are now in an era where personalized medicine and targeted therapies may give new hope for this patient group [2,3]. Identification of novel molecular markers which can improve diagnosis and prognostic stratification and serve as possible therapeutic targets will be of great importance in the near future.

MicroRNAs (miRNAs) are small non-coding nucleotides. They post-transcriptionally control the stability and translation of mRNAs. Today, we know more than

\footnotetext{
* Correspondence: Helge.Stenvold@uit.no

'Institute of Clinical Medicine, University of Tromso, Tromso, Norway ${ }^{2}$ Department of Oncology, University Hospital of North Norway, Tromso 9038, Norway

Full list of author information is available at the end of the article
}

1500 different miRNAs, and each miRNA can regulate several genes [4]. Many miRNAs are located at sites of the genome known to be altered in cancers, and are frequently up- or down regulated [5]. The differences in miRNA expression between cancers make it possible to develop specific miRNA profiles for different cancer types [6].

miR-182 is one of the miRNAs often seen upregulated in cancers. Also in NSCLC, several studies have reported miR-182 to be up-regulated, and it is generally regarded as an oncogene [7-11]. However, results are conflicting concerning its role as an oncogene or tumor suppressor. In NSCLC and other malignancies, high miR-182 expression has been associated with cell migration, metastatic properties of cancer cells and poor survival [11-13]. Recent studies have, however, found miR-182 to suppress lung cancer cell proliferation and growth of melanoma cells [14-16].

In a recent study, we screened tumor tissues from 10 worst and 10 best prognosis NSCLC cases as well as 10

\section{() Biomed Central}

(c) 2014 Stenvold et al.; licensee BioMed Central Ltd. This is an Open Access article distributed under the terms of the Creative Commons Attribution License (http://creativecommons.org/licenses/by/2.0), which permits unrestricted use, distribution, and reproduction in any medium, provided the original work is properly credited. 
normal lungs for the expression of several angiogenesisrelated miRNAs [17]. miR-182 was the only miRNA among 281 tested to be up-regulated in all three comparisons: worst prognosis versus normal lung, best prognosis versus normal lung and worst prognosis versus best prognosis [17]. Besides, miR-182 appeared to be connected to angiogenesis according to the Gene Set Enrichment Analyses (GSEA) [17].

Based on these pilot data, we have explored the impact of miR-182 in our large unselected cohort of 335 NSCLC cases. In situ hybridization was performed on tissue micro array slides for high-throughput exploration of miR-182's prognostic impact. Since it is known that miRNAs are highly tissue- and stage specific and miR-182, in particular, possibly connected to angiogenesis according to the GSEA, we aimed to explore 1) the prognostic impact of miR-182 also in the NSCLC subgroups and 2) its association with relevant angiogenic and hypoxia molecular markers.

\section{Methods}

\section{Patients and clinical samples}

Between 1990 and 2004, 371 patients with pathological stage I to IIIA non-small cell lung cancer were diagnosed at the University Hospital of North Norway and Nordland Central Hospital and treated with curative intent. Resected tissues from the primary tumors in these patients were used in our retrospective study. Out of 371 patients, 36 were excluded from the study due to radiotherapy or chemotherapy prior to surgery $(n=10)$, other malignancy within 5 years before NSCLC diagnosis $(n=13)$ or inadequate paraffin-embedded fixed tissue blocks $(n=13)$. Adjuvant chemotherapy was not introduced in Norway during this period (1990 - 2004). Thus, 335 patients with complete demographic and clinicopathological data were eligible for this study. Of these, postoperative radiotherapy was offered to 55 patients with non-radical surgical margins or mediastinal lymph node disease (N2).

This report includes follow-up data as of January 10, 2011. The median follow-up time of survivors was 105 months (range 73-234). Formalin-fixed, paraffinembedded tumor specimens were obtained from the archives of the Departments of Clinical Pathology at the University Hospital of North Norway and Nordland Central Hospital. The pathological data were revised according to the $7^{\text {th }}$ edition of UICC TNM classification of lung cancer [18]. If the morphological characteristics for adeno- and squamous cell carcinomas were easily recognizable, it was not always necessary to do further examinations (IHC) of the tumor samples. If the tumors were not well differentiated, IHC was necessary. CK7, TTF1, p63 and CK5/6 was the markers most frequently used. The National Data Inspection Board and the
Regional Ethics Committee North (REC North) approved this study.

\section{Microarray construction}

We used a $0.6 \mathrm{~mm}$-diameter stylet to sample two cores with neoplastic tissue and two cores with tumor stroma from different areas of the primary tumors from each patient. Normal lung tissue localized distant from the tumor and lung tissue sample from 20 patients without cancer diagnosis were used as controls. The TMAs were assembled using a tissue-arraying instrument (Beecher Instruments, Silver Springs, Md). Eight tissue microarray blocks were made to include all the tissue samples. Multiple 4- $\mu \mathrm{m}$-sections were cut with a Micron microtome (HM355S) and stained by specific antibodies for immunohistochemical analyses or stained by in situ hybridization. The detailed methodology has been previously reported [19].

\section{In situ hybridization (ISH)}

In situ hybridization was performed following the protocol developed by Exiqon, Vedbaek, Denmark [20]. Digoxigenin (DIG) labelled locked nucleic acid (LNA) modified probes from Exiqon for miR-182 (hsa-miR182), positive control (U6, hsa/mmu/rno) and negative control (scramble-miR) were used in this study. Some adjustments were done to get a specific and sensitive detection of miRNA in our sections from formalin-fixed paraffin-embedded (FFPE) TMA blocks.

We placed $4 \mu \mathrm{m}$ sections of the TMA blocks in a heater at $59^{\circ} \mathrm{C}$ over night to attach cores to Super Frost Plus slides. Sections were deparaffinised with xylene $(3 \times 5 \mathrm{~min})$ and then rehydrated with ethanol solutions $(99.9 \%-96 \%$ $70 \%)$ ending up in PBS, pH 7.4. Proteinase-K $(20 \mu \mathrm{g} / \mathrm{ml})$ (Exiqon, Vedbaek, Denmark) treatment was done in PKbuffer (5 mM Tris-HCl, pH 7.5, $1 \mathrm{mM}$ EDTA, $1 \mathrm{mM}$ $\mathrm{NaCl}$, autoclaved) at $37^{\circ} \mathrm{C}$ for $20 \mathrm{~min}$ in a HYBrite automated hybridizer (Abbot laboratories, IL, US). After a PBS wash the sections were dehydrated through increasing gradient of ethanol solutions and air-dried. The LNAprobes were denatured by heating to $90^{\circ} \mathrm{C}$ for $4 \mathrm{~min}$. Hybridization of the LNA-probe miR-182 (100nM) and scramble $\mathrm{miR}(50 \mathrm{nM})$ control was carried out in the HYBrite automated hybridizer at $50^{\circ} \mathrm{C}$ for $60 \mathrm{~min}$. The positive control U6 (1nM) was hybridized at $55^{\circ} \mathrm{C}$ for $60 \mathrm{~min}$. Stringent washes was performed in pre-heated SSC buffers, $1 \times 5 \mathrm{~min}$ in $5 \mathrm{x} \mathrm{SSC}, 2 \times 5 \mathrm{~min}$ in $1 \times$ SSC and $0,2 \times$ SSC. Sections were blocked against unspecific binding in blocking solution from DIG wash and Block Buffer set (Roche, Mannheim, Germany) for $15 \mathrm{~min}$ at room temperature (RT). Alkaline phosphatase (AP)-conjugated anti-DIG (Roche) 1:800 was incubated for $60 \mathrm{~min}$ at RT for immunologic detection. After PBS-T wash the substrate enzymatic reaction was carried out with NBT/ 
$\mathrm{BCIP}$ (Roche) at $30^{\circ} \mathrm{C}$ in the hybridizer for $120 \mathrm{~min}$. The reaction was stopped with a $2 \times 5$ min wash in KTBT buffer (50 mM Tris- $\mathrm{HCl}, 150 \mathrm{mM} \mathrm{NaCl}, 10 \mathrm{mM}$ $\mathrm{KCl})$. Sections were counter stained with nuclear fast red (WALDECK, ZE-012-250) at RT for 1 min and then rinsed in tap water. Dehydration followed through increasing gradient of ethanol solutions and finally mounting with Histokitt mounting medium (Assistant-Histokitt, 1025/250).

\section{Immunohistochemistry (IHC)}

We used data from previous publications with the following antibodies for correlation analyses: $\operatorname{VEGF}(-\mathrm{A},-\mathrm{C},-\mathrm{D}$, $\mathrm{R}-1, \mathrm{R}-2, \mathrm{R}-3)$, PDGF $(-\mathrm{A},-\mathrm{B},-\mathrm{C},-\mathrm{D}, \mathrm{R}-\alpha, \mathrm{R}-\beta)$, FGF $(-2$, R-1), Notch $(-1,-2)$, Jagged1, DLL4, Hif $(-1 \alpha,-2 \alpha)$, GLUT-1, LDH5, CAIX, PHD $(-1,-2,-3)$, FIH, Ang $(-1,-2,-4)$, Tie- 2 and MMP $(-2,-7,-9)$. Detailed IHC procedures for the antibodies which correlated significantly with miR-182 (FGF2, Hif2 $\alpha$ and MMP-7) have been previously published [21-23].

\section{Scoring of ISH}

Representative viable tissue sections were scored semiquantitatively by light microscopy. The dominant staining intensity in tumor cells was scored as $0=$ negative, $1=$ weak, 2 = intermediate or $3=$ strong (Figure 1 ). The TMA cores were scored anonymously and independently by one experienced pathologist and one oncologist. In case of disagreement, the slides were reexamined and consensus was reached by the observers.

Mean score for duplicate cores from each individual was calculated in tumor epithelial cells. We then categorized the staining into high and low expression. High expression in tumor cells was defined as score $>0$.

\section{Statistical methods}

All statistical analyses were performed using the statistical package SPSS (Chicago, IL), version 19.0. The chi-square test and the Fisher exact test were used to examine the association between molecular marker expression and the clinicopathological markers. Correlations between markers were assessed using Spearman's rank correlation. Univariate analyses were done using the Kaplan-Meier method, and statistical significance between survival curves was assessed by the log-rank test. Disease-specific survival (DSS) was defined as time from surgery to lung cancer death. Variables of significant value from the univariate analyses were entered into multivariate analysis using the backward stepwise Cox regression analysis. A $\mathrm{P}<0.05$ was considered statistically significant.

\section{Ethics}

The National Data Inspection Board and the Regional Ethics Committee North (REC North) approved this study. Information and subsequent written consent from patients was considered, but as this was a retrospective
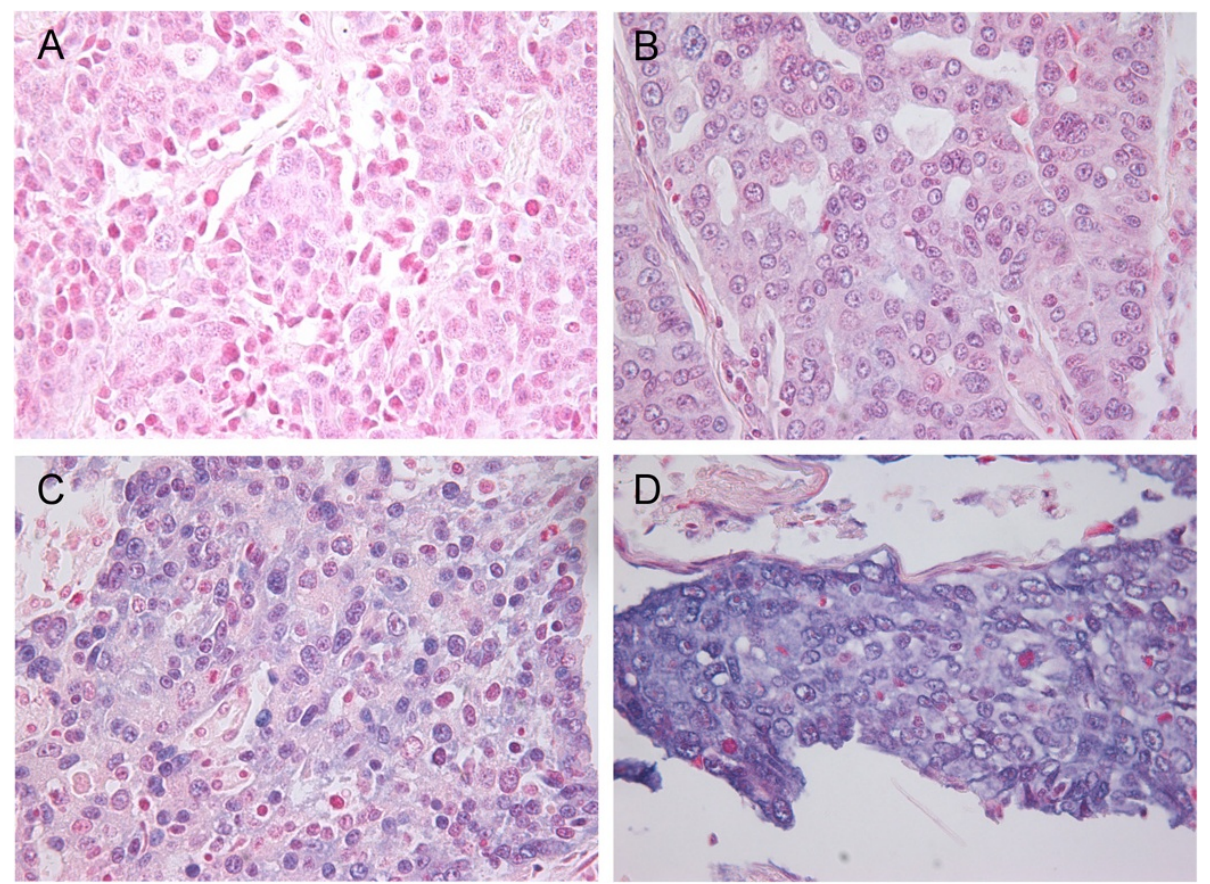

Figure 1 In situ hybridization (ISH) analysis of non-small-cell lung cancer. Scoring intensities based on blue cytoplasmatic staining graded from 0-3 in tumor cells. A: score 0; B: score 1; C: score 2; $\mathbf{D}$; score 3. 
study with more than half of patients deceased, the rest of the patients having to be reminded about the death rate of the disease and the possible raising of unrealistic hope for the individual, The Norwegian Data Inspection Board and REC North specifically waived the need for consent. All the patient data were anonymized after collecting the clinicopathological variables for each patient and before doing the statistical analyses.

\section{Results}

\section{Patient characteristics}

Demographic, clinical and histopathological variables are listed in Table 1. The median patient age was 67 (range 28-85) and the majority were male (76\%). Most patients (95\%) were current or previous smokers. The NSCLC tumors comprised 191 squamous cell carcinomas (SCC), 113 adenocarcinomas (AC) including 18 bronchioloalveolar carcinomas (BAC) and 31 large-cell carcinomas (LCC).

\section{Expression of miR-182 and correlations}

miR-182 was homogenously expressed mainly in the cytoplasm of tumor cells. There was also some unspecific nuclear staining (Figure 1). The scoring was based on cytoplasmic staining. There was no staining of stromal cells, except for weak nuclear staining of some fibroblasts.

We tested correlations between miR-182 and angiogenic and hypoxia molecular markers. We found significant correlations between miR-182 and FGF2 $(\mathrm{r}=-0.147 ; \mathrm{P}=$ $0.010)$, HIF $2 \alpha(\mathrm{r}=0.115 ; \mathrm{P}=0.047)$ and MMP-7 $(\mathrm{r}=0.172$; $\mathrm{P}=0.003)$.

\section{Univariate analysis}

As shown in Table 1, the clinicopathological variables performance status $(\mathrm{P}=0.016)$, histology $(\mathrm{P}=0.028)$, tumor differentiation $(\mathrm{P}<0.001)$, surgical procedure $(\mathrm{P}=0.007)$, pathological stage $(\mathrm{P}<0.001)$, tumor status $(\mathrm{P}<0.001)$, nodal status $(\mathrm{P}<0.001)$ and vascular infiltration $(\mathrm{P}=0.001)$ were significant prognostic indicators for DSS.

The results from the univariate analyses on miR-182 are presented in Table 2 and Figures 2 and 3. In the whole cohort, there was a tendency towards a better prognosis for those with tumors overexpressing miR$182(\mathrm{P}=0.062$, Figure 2$)$. In subgroup analyses, patients with stage II disease had a significantly improved prognosis if they overexpressed miR-182 ( $\mathrm{P}=0.003$, Figure $3 \mathrm{E})$. In the histological subgroup SCC, high tumor cell miR182 expression was associated with superior prognosis when compared to low expression $(\mathrm{P}=0.042$, Figure $3 \mathrm{~A}$ ), while for large cell carcinomas the trend was opposite (Figure 3C).

\section{Multivariate analysis}

In the total cohort, performance status $(\mathrm{P}=0.008)$, histology $(\mathrm{P}=0.001)$, tumor differentiation $(\mathrm{P}=0.007)$, tumor status $(\mathrm{P}=0.007)$, nodal status $(\mathrm{P}=0.022)$ and vascular infiltration $(\mathrm{P}=0.004)$ all were independent prognostic factors.

Results of the multivariate analysis for miR-182 expression are presented in Table 2. Examining the total material, high miR-182 expression tended towards an independent association with a better prognosis (HR 0.73, CI 95\% 0.50-1.06, $\mathrm{P}=0.098$ ). Among stage II patients, however, high tumor cell expression of miR-182 was an independent positive prognostic factor (HR 0.50, CI 95\% 0.28-0.90, $\mathrm{P}=0.020)$. Also in SCC, patients with a high miR-182 expression had an independent favorable outcome (HR 0.57, CI 95\% 0.33-0.99, P = 0.048).

\section{Co-expression of miR-182 with FGF2 and MMP-7}

Among markers examined for correlations with miR182, FGF2 and MMP-7 showed the strongest correlations. We assessed the co-expression combinations between miR-182 and FGF2 and MMP-7, respectively. The co-expression of low miR-182/high FGF2 was associated with poor survival $(\mathrm{P}=0.017)$ as shown in Figure $4 \mathrm{~A}$. The combination showed an independently significant adverse prognosis compared to high miR-182/low FGF2 (HR 1.92, $\mathrm{P}=0.015$, Table 3). Patients expressing high miR-182/high MMP-7 had a better survival than other combinations $(P=0.036$, Figure $4 \mathrm{~B})$. In the multivariate analyses, high miR-182/high MMP-7 showed an independently better prognosis than low miR-182/low MMP-7 (HR $0.49, \mathrm{P}=0.015$, Table 3 ). In the SCC subgroup, we found an even bigger difference between these groups both in univariate and multivariate analyses (Figure $4 \mathrm{C}$, Table 3).

\section{Discussion}

In a large unselected cohort of NSCLC patients we found miR-182 to be an independent positive prognostic factor in stage II patients and in patients with squamous cell carcinoma. We are, to our knowledge, the first group evaluating the prognostic impact of miR-182 in NSCLC using in situ hybridization.

Barshack and coworkers showed that miR-182 was over-expressed in primary lung tumors relative to metastases to the lung [24]. In another study by the same group, a set of different miRNAs could be used to differentiate hepatocellular carcinomas from metastatic tumors in the liver [25]. miRNA expression differs between tumor types, within the same tumor type in different patients and between primary tumors and metastases. Hence, it may not be surprising to find miR-182 to have divergent impact in different stages of NSCLC. 
Table 1 Patient characteristics and their variables as predictors for disease-spesific survival in 335 NSCLC patients (univariate analyses; log-rank test)

\begin{tabular}{lcccc}
\hline Characteristics & Patients & $\begin{array}{l}\text { Median } \\
\text { survival }\end{array}$ & $\begin{array}{c}5 \text {-year } \\
\text { survival }\end{array}$ & $\mathrm{P}$ \\
& $\mathrm{n}$ & $(\%)$ & months & $\%$
\end{tabular}

Age

$\leq 65$ years $\quad 156(47) \quad 98$

$>65$ years $\quad 179 \quad(53) \quad$ NR

Sex

$\begin{array}{lcccc}\text { Female } & 82 & (24) & 190 & 64 \\ \text { Male } & 253 & (76) & 98 & 56\end{array}$

Smoking

Never

Current

Former

Performance status

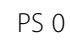

197 (59)

PS 1

PS 2

Weight loss

$$
<10 \%
$$

$>10 \%$

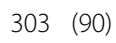

Histology

SCC

Adenocarcinoma

LCC

Differentiation

Poor $\quad 138$ (41)

Moderate $\quad 144$ (43)

Well

Surgical procedure

wedge $^{*}$

Pneumonectomy

$243(73)$

Pathological stage

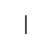

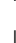$$
\text { II }
$$

Illa

Tumor status

1
2
3

\section{Nodal status}

1

2
$15 \quad(5)$

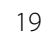

215 (64)

105 (31)

120 (36)

$18 \quad(5)$

32 (10)

53 (16)

190

37

98

56

Table 1 Patient characteristics and their variables as predictors for disease-spesific survival in 335 NSCLC patients (univariate analyses; log-rank test) (Continued)

Surgical margins

$\begin{array}{lccccc}\text { Free } & 307 & (92) & 190 & 59 & 0.37 \\ \text { Not free } & 28 & (8) & 47 & 48 & \end{array}$

Vascular infiltration

$\begin{array}{lccccc}\text { No } & 284 & (85) & 190 & 62 & \mathbf{0 . 0 0 1} \\ \text { Yes } & 51 & (15) & 27 & 33 & \end{array}$

Statistically significant results in bold font.

*Wedge, $\mathrm{n}=10$.

Abbreviations: NR not reached, PS performance status, SCC squamos cell carcinoma, LCC large-cell carcinoma. Adenocarcinoma including cases with bronchioloalveolar carcinoma.

Increasing evidence demonstrate that adenocarcinomas and SCC of the lung are separate lung cancer entities, have dissimilar features and may respond differently to therapy. Targeted drugs with specific effects in certain histological subgroups have been developed. Certain miRNA-signatures can differentiate SCC from nonSCC and may facilitate the distinction between them [26]. Demonstrating a significant prognostic effect by miR-182 in SCC and not in adenocarcinomas underscores the diversity between the histological subgroups. In a previous published paper from our group [27], we explored the impact of miR-155 in the same cohort. We found this miRNA to be very stage- and tissue specific, with a significant impact on survival only in node positive SCC patients.

miR-182 has been regarded as an oncogene in most contexts. In a cohort of 253 glioma patients, high miR-182 expression was found to be a negative prognostic factor [12]. In melanoma cell lines, Segura and coworkers showed that high miR-182 expression stimulated migration and survival. The same group treated liver metastases in mice with anti-miR-182 and obtained a lower tumor burden and a lower mir-182-level than in untreated mice [13,28]. Also in breast tumors and cervical cancers miR-182 seems to have an oncogenic impact $[29,30]$.

There are other studies that have identified miR-182 as a tumor suppressor. Kong et al. found miR-182 to be underexpressed in human gastric cancer cell lines. They showed that the oncogene cAMP responsive element binding protein 1 (CREB1) is a target of miR-182, and that high levels of miR-182 leads to lower levels of CREB1 and suppressed gastric adenocarcinoma cell growth [31]. In melanoma cell lines, Poell et al. found miR-182 to be a strong inhibitor of cell proliferation [14]. Yan and coworkers found similar effects in uveal melanoma cells, where they identified MITF, BCL2 and cyclin D2 as potential targets of miR-182. Transfection of miR-182 into cultured uveal melanoma cells led to a 
Table 2 miR-182 in tumor cells and stroma as predictors for disease-specific survival in NSCLC patients (univariate analysis; log-rank test) and results of Cox regression analysis summarizing significant independent prognostic factors

\begin{tabular}{|c|c|c|c|c|c|c|c|}
\hline Characteristics & Pts (n) & Pts (\%) & Median survival (months) & 5-year survival (\%) & Univariate $(P)$ & Multi-variate $(\mathrm{P})$ & $\mathrm{HR}(95 \% \mathrm{Cl})$ \\
\hline Total $(n=335)$ & & & & & 0.062 & 0.098 & 0.73 \\
\hline Low & 190 & 57 & 98 & 55 & & & $(0.50-1.06)$ \\
\hline High & 115 & 34 & NR & 62 & & & \\
\hline Missing & 30 & 9 & & & & & \\
\hline \multicolumn{8}{|l|}{ Pathological stage } \\
\hline Stage I $(n=143)$ & & & & & 0.97 & NE & NE \\
\hline Low & 87 & 61 & 190 & 73 & & & \\
\hline High & 56 & 39 & NR & 73 & & & \\
\hline Stage II $(n=127)$ & & & & & 0.003 & 0.020 & 0.50 \\
\hline Low & 80 & 63 & 33 & 39 & & & $0.28-0.90$ \\
\hline High & 47 & 37 & NR & 63 & & & \\
\hline Stage III $(n=35)$ & & & & & 0.69 & NE & NE \\
\hline Low & 23 & 66 & 23 & 39 & & & \\
\hline High & 12 & 34 & 15 & 17 & & & \\
\hline \multicolumn{8}{|l|}{ Histology } \\
\hline $\operatorname{SCC}(n=172)$ & & & & & 0.042 & 0.048 & 0.57 \\
\hline Low & 104 & 60 & NR & 58 & & & $0.33-0.99$ \\
\hline High & 68 & 40 & NR & 74 & & & \\
\hline AC $(n=106)$ & & & & & 0.316 & NE & $N E$ \\
\hline Low & 69 & 65 & 47 & 45 & & & \\
\hline High & 37 & 35 & 57 & 50 & & & \\
\hline LCC $(n=27)$ & & & & & 0.285 & NE & NE \\
\hline Low & 17 & 63 & NR & 80 & & & \\
\hline High & 10 & 37 & 58 & 39 & & & \\
\hline
\end{tabular}

Statistically significant results in bold font.

Abbreviations: NR not reached, PS performance status, SCC squamous cell carcinoma, AC adenocarcinoma, LCC large-cell carcinoma, NE not entered due to insignificance. Adenocarcinoma including cases with bronchioloalveolar carcinoma.

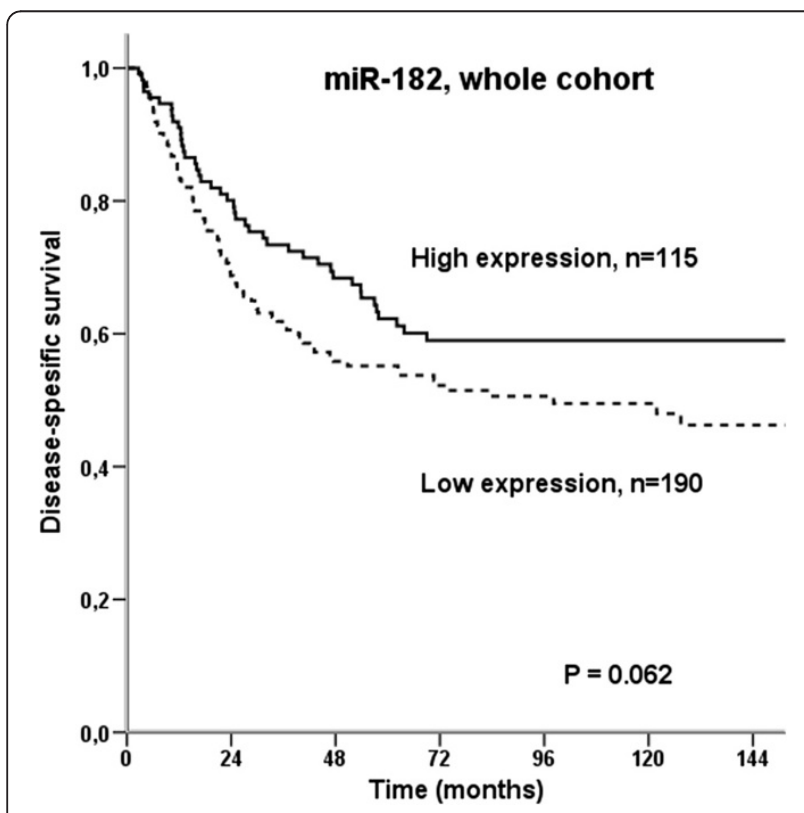

Figure 2 Disease-specific survival curves according to tumor cell expression of miR-182 in the whole cohort of patients. significant decrease in cell growth, migration and invasiveness [16].

In lung cancer, data on miR-182 have been conflicting regarding its prognostic role. In 70 lung cancer tissue samples, Zhu and coworkers observed an association between high expression of the members of the miR-183 family (miR-96, miR-182 and miR-183) and poor overall survival [11]. In contrast, two in vitro studies using cell lines did not support the notion of miR-182 exerting an oncogene role in lung cancer. Sun et al. found miR-182, through regulation of RGS17, to suppresses lung tumorigenesis [15]. Consistently, Zhang and coworkers reported miR-182 to inhibit proliferation and invasion of human lung adenocarcinoma cells via its effect on human cortical actin-associated protein (CTTN) [32].

miR-182 has a number of target genes, and it is evident that the regulation of these genes can result in both inhibition and stimulation of tumorigenesis. In NSCLC, our results suggest that tumor inhibiting miR-182 features dominate and thus make this miRNA a favorable prognostic factor. 


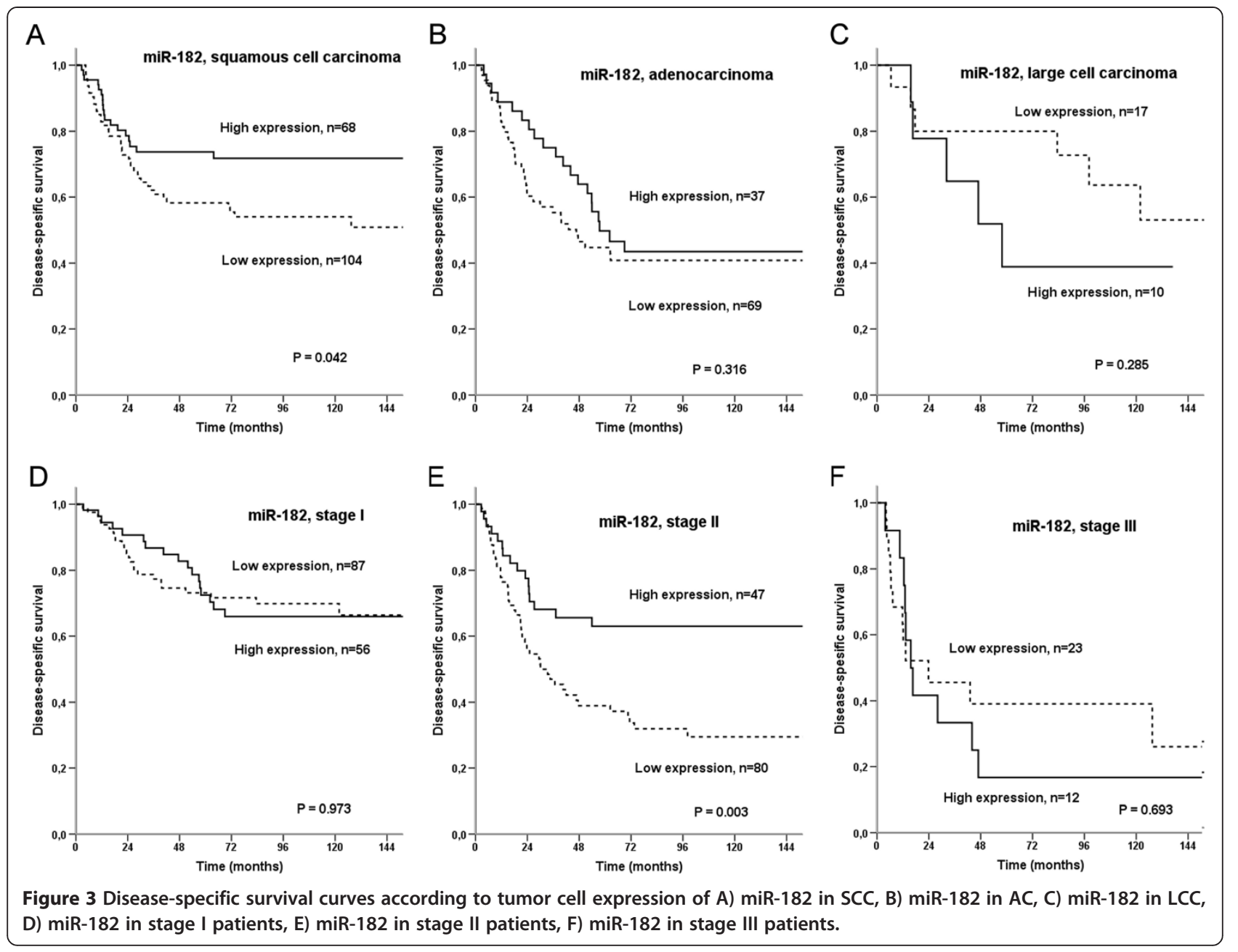

Based on the association with angiogenesis suggested from the GSEA [17], we investigated the correlation between miR-182 and a set of angiogenesis-related protein markers. There was a negative correlation between miR182 and FGF2. Our group has published data on FGF2, which identify this marker as an independent negative prognostic factor in lung cancer cells [22]. Fibroblast growth factor receptor substrate 2 (FRS2) is a downstream mediator of the fibroblast growth factor pathway and is a target gene of miR-182. FRS2 is thought to induce tumor progression through stimulation of angiogenesis [17,33]. In our total NSCLC cohort, the coexpression between miR-182 and FGF2 showed an independent significantly worse prognosis for low miR182/high FGF2 than for high miR-182/low FGF2 ( $\mathrm{P}=$ 0.015 , Table 3).

A correlation was also detected between miR-182 and MMP-7. In a previous paper, our group found high MMP-7 expression to be an independent favorable prognostic factor in this same NSCLC cohort [23]. When examining coexpression of the two variables, those with high miR-182 and high MMP-7 expression had an independently better survival than those with low miR182/low MMP-7 expression (HR 0.49, P = 0.015). When stratifying on histology, the SCC patients with high/high expression had a remarkably better prognosis than the rest of the groups (HR 0.26, P = 0.012, Table 3).

To our knowledge, there are no published data linking miR-182 and MMP-7. Few studies have described the connection between FGF2 and MMP-7 [34,35]. Based on our strong results from the co-variations between miR-182 and particularly MMP-7, it would be interesting to see functional studies exploring potential relations between these two markers.

In our previous pilot study on miRNA signatures [17], miR-182 appeared as an oncogene since it was upregulated in short vs long term NSCLC survivors and in NSCLC vs normal tissues. In our large unselected NSCLC cohort presented herein, we surprisingly observed that high miR-182 expression is associated with improved survival, at least in subgroups of patients with NSCLC. It has to be kept in mind that the explorative study was based on a small sample, only 20 NSCLC cases and 10 normal lung tissues. Hence, the contrasting 

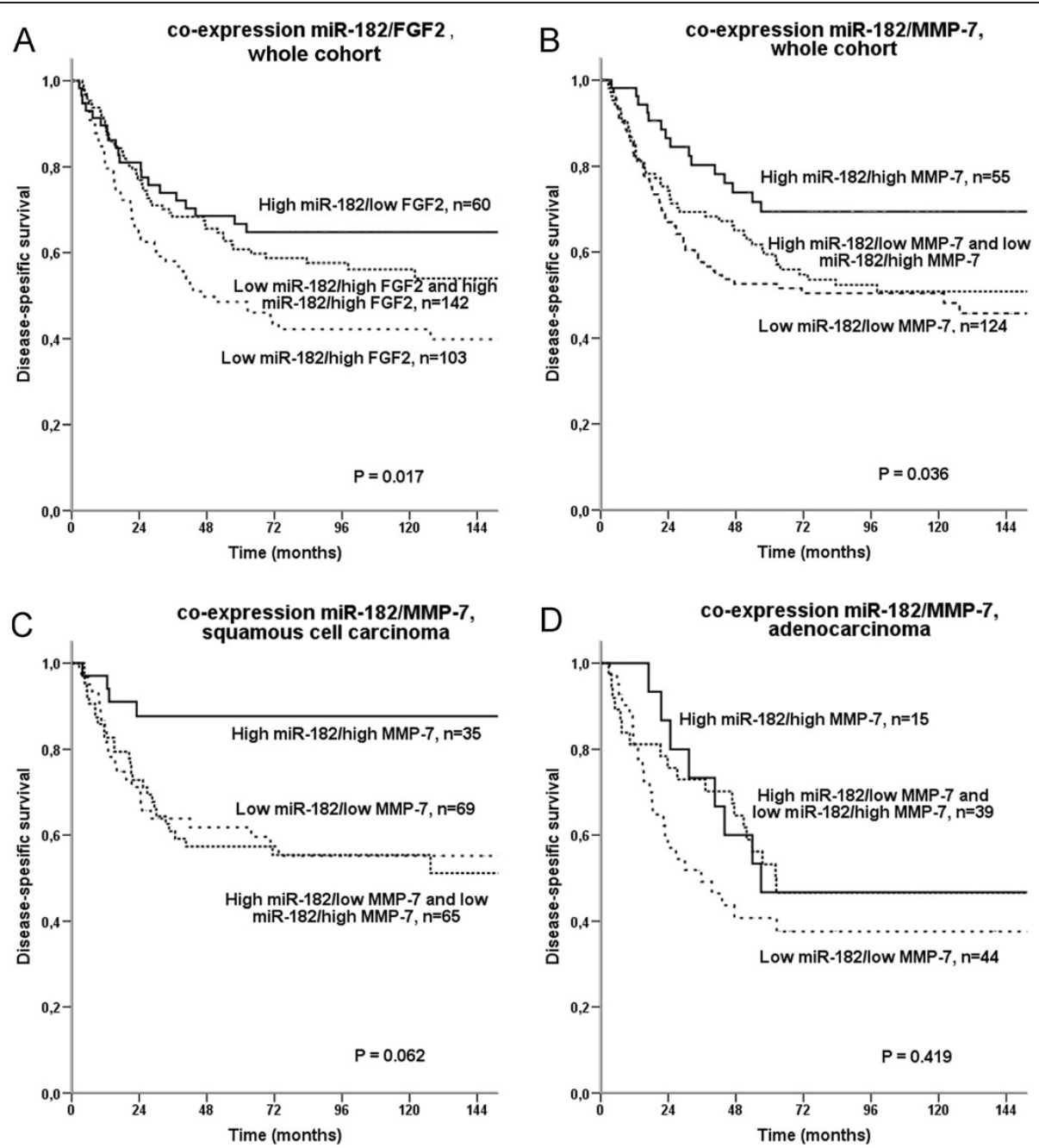

Figure 4 Disease-specific survival curves according to tumor cell co-expression of miR-182 and A) FGF2 in the whole cohort of patients, B) MMP-7 in the whole cohort of patients, C) MMP-7 in SCC, and D) MMP-7 in AC.

Table 3 Results of Cox regression analysis summarizing co-expressions of miR-182 with FGF2 and MMP-7, respectively

\begin{tabular}{|c|c|c|c|}
\hline & Hazard ratio & $95 \% \mathrm{Cl}$ & $\mathbf{P}$ \\
\hline Co-expression of miR-182/FGF2 & & & 0.021 \\
\hline High miR-182/low FGF2 & 1.00 & & \\
\hline $\begin{array}{l}\text { High miR-182/high FGF2 and } \\
\text { low miR-182/low FGF2 }\end{array}$ & 1.26 & $0.74-2.13$ & 0.39 \\
\hline Low miR-182/high FGF2 & 1.92 & $1.14-3.24$ & 0.015 \\
\hline Co-expression of miR-182/MMP-7 & & & 0.032 \\
\hline Low miR-182/low MMP-7 & 1.00 & & \\
\hline $\begin{array}{l}\text { Low miR-182/high MMP-7 and } \\
\text { high miR-182/low MMP-7 }\end{array}$ & 0.71 & $0.48-1.05$ & 0.086 \\
\hline High miR-182/high MMP-7 & 0.49 & $0.27-0.87$ & 0.015 \\
\hline $\begin{array}{l}\text { Co-expression of miR-182/MMP-7, } \\
\text { squamous cell carcinoma }\end{array}$ & & & 0.040 \\
\hline Low miR-182/low MMP-7 & 1.00 & & \\
\hline $\begin{array}{l}\text { Low miR-182/high MMP-7 and } \\
\text { high miR-182/low MMP-7 }\end{array}$ & 0.80 & $0.46-1.37$ & 0.41 \\
\hline High miR-182/high MMP-7 & 0.26 & $0.090-0.74$ & 0.012 \\
\hline
\end{tabular}

Statistically significant results in bold font. results may be due, at least in part, to selection bias in the explorative study. Besides, in the present study the favorable prognostic impact by miR-182 was seen in subgroups of NSCLC patients, and assessments were tissue specific (only in tumor cells) using in situ hybridization and not real time qPCR, as in the pilot study [17]. When using qPCR a contribution from the stromal compartment will influence the result, and the stromal expression of miR-182 may be different from that of the tumor cells.

\section{Conclusion}

In conclusion, miR-182 tended to be a favorable prognostic factor in the total NSCLC cohort. Moreover, in stage II and in SCC patients we found miR-182 to have tumor suppressor properties. Nevertheless, our study must be regarded as hypotheses generating, and needs to be confirmed in other cohorts and functional studies. We found a weak, but significant association between 
mir-182 and the angiogenesis related markers FGF2 and MMP-7. It would be interesting to see further studies exploring these associations.

\section{Competing interests}

The authors declare that they have no competing interests.

\section{Authors' contributions}

HS participated in the design of the study, contributed to the clinical and demographic database, did the statistical analysis and drafted the manuscript. TD, SA and SAS contributed to the clinical and demographic database and SAS in making the TMAs. TD and SA contributed to the statistical analysis. SAS and HS scored the cores. RMB and LTB supervised and participated in the study design, result interpretation and writing. All authors read and approved the final manuscript.

\section{Acknowledgements}

The study was solely funded by the Northern Norway Regional Health Authority (Helse Nord RHF) which is responsible for the public hospitals in northern Norway. The funders had no role in study design, data collection and analysis, decision to publish, or preparation of the manuscript. The authors thank the engineers Mona I Pedersen and Marta Uso, who carried out the ISH-procedures.

\section{Author details}

'Institute of Clinical Medicine, University of Tromso, Tromso, Norway. ${ }^{2}$ Department of Oncology, University Hospital of North Norway, Tromso 9038, Norway. ${ }^{3}$ Institute of Medical Biology, University of Tromso, Tromso, Norway. ${ }^{4}$ Department of Clinical Pathology, University Hospital of North Norway, Tromso, Norway.

Received: 25 April 2013 Accepted: 12 February 2014

Published: 27 February 2014

\section{References}

1. Jemal A, Siegel R, Xu J, Ward E: Cancer statistics, 2010. CA Cancer J Clin 2010, 60:277-300

2. Drilon A, Rekhtman N, Ladanyi M, Paik P: Squamous-cell carcinomas of the lung: emerging biology, controversies, and the promise of targeted therapy. Lancet Oncol 2012, 13:e418-e426.

3. Ma PC: Personalized targeted therapy in advanced non-small cell lung cancer. Cleve Clin J Med 2012, 79(Electronic Suppl 1):eS56-eS60.

4. Kasinski AL, Slack FJ: Epigenetics and genetics. MicroRNAs en route to the clinic: progress in validating and targeting microRNAs for cancer therapy. Nat Rev Cancer 2011, 11:849-864.

5. Calin GA, Sevignani C, Dumitru CD, Hyslop T, Noch E, Yendamuri S, Shimizu M, Rattan S, Bullrich F, Negrini M, Croce CM: Human microRNA genes are frequently located at fragile sites and genomic regions involved in cancers. Proc Natl Acad Sci U S A 2004, 101:2999-3004.

6. Calin GA, Croce CM: MicroRNA signatures in human cancers. Nat Rev Cancer 2006, 6:857-866.

7. Cho WC, Chow AS, Au JS: Restoration of tumour suppressor hsa-miR-145 inhibits cancer cell growth in lung adenocarcinoma patients with epidermal growth factor receptor mutation. Eur J Cancer 2009, 45:2197-2206.

8. Guan P, Yin Z, Li X, Wu W, Zhou B: Meta-analysis of human lung cancer microRNA expression profiling studies comparing cancer tissues with normal tissues. J Exp Clin Cancer Res 2012, 31:54.

9. Tan X, Qin W, Zhang L, Hang J, Li B, Zhang C, Wan J, Zhou F, Shao K, Sun Y, Wu J, Zhang X, Qiu B, Li N, Shi S, Feng X, Zhao S, Wang Z, Zhao X, Chen Z, Mitchelson K, Cheng J, Guo Y, He J: A 5-microRNA signature for lung squamous cell carcinoma diagnosis and hsa-miR-31 for prognosis. Clin Cancer Res 2011, 17:6802-6811.

10. Zheng D, Haddadin S, Wang Y, Gu LQ, Perry MC, Freter CE, Wang MX: Plasma microRNAs as novel biomarkers for early detection of lung cancer. Int J Clin Exp Pathol 2011, 4:575-586.

11. Zhu W, Liu X, He J, Chen D, Hunag Y, Zhang YK: Overexpression of members of the microRNA-183 family is a risk factor for lung cancer: a case control study. BMC Cancer 2011, 11:393.

12. Jiang L, Mao P, Song L, Wu J, Huang J, Lin C, Yuan J, Qu L, Cheng SY, Li J: miR-182 as a prognostic marker for glioma progression and patient survival. Am J Pathol 2010, 177:29-38.
13. Segura MF, Hanniford D, Menendez S, Reavie, L, Zou X, Alvarez-Diaz S, Zakrzewski J, Blochin E, Rose A, Bogunovic D, Polsky D, Wei J, Lee P, Belitskaya-Levy I, Bhardwaj N, Osman I, Hernando E: Aberrant miR-182 expression promotes melanoma metastasis by repressing $\mathrm{FOXO} 3$ and microphthalmia-associated transcription factor. Proc Natl Acad Sci U S A 2009, 106:1814-1819.

14. Poell JB, van Haastert RJ, de Gunst T, Schultz IJ, Gommans WM, Verheul M, Cerisoli F, van Noort PI, Prevost GP, Schaapveld RQ, Cuppen E: A functional screen identifies specific microRNAs capable of inhibiting human melanoma cell viability. PLoS One 2012, 7:e43569.

15. Sun Y, Fang R, Li C, Li L, Li F, Ye X, Chen H: Hsa-mir-182 suppresses lung tumorigenesis through down regulation of RGS17 expression in vitro. Biochem Biophys Res Commun 2010, 396:501-507.

16. Yan D, Dong XD, Chen X, Yao S, Wang L, Wang J, Wang C, Hu DN, Qu J, Tu L: Role of microRNA-182 in posterior uveal melanoma: regulation of tumor development through MITF, BCL2 and cyclin D2. PLOS One 2012, 7:e40967.

17. Donnem T, Fenton CG, Lonvik K, Berg T, Eklo K, Andersen S, Stenvold H, Al-Shibli K, Al-Saad S, Bremnes RM, Busund LT: MicroRNA signatures in tumor tissue related to angiogenesis in Non-small cell lung cancer. PLoS One 2012, 7:e29671.

18. Rami-Porta R, Chansky K, Goldstraw P: Updated lung cancer staging system. Future Oncol 2009, 5:1545-1553.

19. Donnem T, Al-Saad S, Al-Shibli K, Delghandi MP, Persson M, Nilsen MN, Busund $L T$, Bremnes RM: Inverse prognostic impact of angiogenic marker expression in tumor cells versus stromal cells in non small cell lung cancer. Clin Cancer Res 2007, 13:6649-6657.

20. Jorgensen S, Baker A, Moller S, Nielsen BS: Robust one-day in situ hybridization protocol for detection of microRNAs in paraffin samples using LNA probes. Methods 2010, 52:375-381.

21. Andersen S, Eilertsen M, Donnem T, Al-Shibli K, Al-Saad S, Busund LT, Bremnes RM: Diverging prognostic impacts of hypoxic markers according to NSCLC histology. Lung Cancer 2011, 72:294-302.

22. Donnem T, Al-Shibli K, Al-Saad S, Busund LT, Bremnes RM: Prognostic impact of fibroblast growth factor 2 in non-small cell lung cancer: coexpression with VEGFR-3 and PDGF-B predicts poor survival. J Thorac Oncol 2009, 4:578-585.

23. Stenvold $H$, Donnem T, Andersen S, Al-Saad S, Al-Shibli K, Busund LT, Bremnes RM: Overexpression of matrix metalloproteinase-7 and -9 in NSCLC tumor and stromal cells: correlation with a favorable clinical outcome. Lung Cancer 2012, 75:235-241.

24. Barshack I, Lithwick-Yanai G, Afek A, Rosenblatt K, Tabibian-Keissar H, Zepeniuk M, Cohen L, Dan H, Zion O, Strenov Y, Polak-Charcon S, Perelman M: MicroRNA expression differentiates between primary lung tumors and metastases to the lung. Pathol Res Pract 2010, 206:578-584.

25. Barshack I, Meiri E, Rosenwald S, Lebanony D, Bronfeld M, Aviel-Ronen S, Rosenblatt K, Polak-Charcon S, Leizerman I, Ezagouri M, Zepeniuk M, Shabes N, Cohen L, Tabak S, Cohen D, Bentwich Z, Rosenfeld N: Differential diagnosis of hepatocellular carcinoma from metastatic tumors in the liver using microRNA expression. Int J Biochem Cell Biol 2010, 42:1355-1362.

26. Lin PY, Yu SL, Yang PC: MicroRNA in lung cancer. Br J Cancer 2010, 103:1144-1148.

27. Donnem T, Eklo K, Berg T, Sorbye SW, Lonvik K, Al-Saad S, Al-Shibli K, Andersen S, Stenvold H, Bremnes RM, Busund LT: Prognostic impact of MiR-155 in non-small cell lung cancer evaluated by in situ hybridization. J Transl Med 2011, 9:6.

28. Huynh C, Segura MF, Gaziel-Sovran A, Menendez S, Darvishian F, Chiriboga L, Levin B, Meruelo D, Osman I, Zavadil J, Marcusson EG, Hernando E: Efficient in vivo microRNA targeting of liver metastasis. Oncogene 2011, 30:1481-1488.

29. Moskwa P, Buffa FM, Pan Y, Panchakshari R, Gottipati P, Muschel RJ, Beech J Kulshrestha R, Abdelmohsen K, Weinstock DM, Gorospe M, Harris AL, Helleday T, Chowdhury D: miR-182-mediated downregulation of BRCA1 impacts DNA repair and sensitivity to PARP inhibitors. Mol Cell 2011, 41:210-220.

30. Tang T, Wong HK, Gu W, Yu MY, To KF, Wang CC, Wong YF, Cheung TH, Chung TK, Choy KW: MicroRNA-182 plays an onco-miRNA role in cervical cancer. Gynecol Oncol 2013, 129:199-208.

31. Kong WQ, Bai R, Liu T, Cai CL, Liu M, Li X, Tang H: MicroRNA-182 targets cAMP-responsive element-binding protein 1 and suppresses cell growth in human gastric adenocarcinoma. FEBS J 2012, 279:1252-1260. 
32. Zhang $L$, Liu $T$, Huang $Y$, Liu J: microRNA-182 inhibits the proliferation and invasion of human lung adenocarcinoma cells through its effect on human cortical actin-associated protein. Int J Mol Med 2011, 28:381-388.

33. Zhou W, Feng X, Wu Y, Benge J, Zhang Z, Chen Z: FGF-receptor substrate 2 functions as a molecular sensor integrating external regulatory signals into the FGF pathway. Cell Res 2009, 19:1165-1177.

34. Ding K, Lopez-Burks M, Sanchez-Duran JA, Korc M, Lander AD: Growth factor-induced shedding of syndecan-1 confers glypican-1 dependence on mitogenic responses of cancer cells. J Cell Biol 2005, 171:729-738.

35. Holnthoner W, Kerenyi M, Groger M, Kratochvill F, Petzelbauer P: Regulation of matrilysin expression in endothelium by fibroblast growth factor-2. Biochem Biophys Res Commun 2006, 342:725-733.

doi:10.1186/1471-2407-14-138

Cite this article as: Stenvold et al: Stage and tissue-specific prognostic impact of miR-182 in NSCLC. BMC Cancer 2014 14:138.

\section{Submit your next manuscript to BioMed Central and take full advantage of:}

- Convenient online submission

- Thorough peer review

- No space constraints or color figure charges

- Immediate publication on acceptance

- Inclusion in PubMed, CAS, Scopus and Google Scholar

- Research which is freely available for redistribution 